\title{
Post-FIB Specimen Preparation of Atom Probe Specimens under Controlled Environments for Correlative Microscopy
}

\author{
C.S. Bonifacio ${ }^{1}$, P. Nowakowski ${ }^{1}$, K. Costello ${ }^{2}$, M.L. Ray ${ }^{1}$, R. Morrison ${ }^{2}$ and P.E. Fischione ${ }^{1}$ \\ 1. E.A. Fischione Instruments, Inc., Export, PA, USA \\ ${ }^{2}$ Quorum Technologies Ltd., East Sussex, UK \\ * Corresponding author: cs_bonifacio@fischione.com
}

Atom probe tomography (APT) is a powerful characterization technique for obtaining three-dimensional structure and materials composition at the atomic scale. Typically, transmission electron microscopy (TEM) and APT techniques are combined for a complete characterization of structure, morphology and chemistry. However, the full potential of these techniques is typically hindered by artifacts from specimen preparation (e.g., Ga implantation) and environmental conditions degrading the specimen's surface (e.g., surface oxidation). Low energy $(<1 \mathrm{kV}) \mathrm{Ar}^{+}$milling has been shown to improve TEM and APT specimens quality by removing Ga damage from FIB preparation [1, 2] and surface oxides [3]. Here, we present a post-FIB specimen preparation of APT specimens under controlled environments using concentrated beam $(<1 \mu \mathrm{m})$, low energy $\mathrm{Ar}^{+}$milling for the removal of surface oxides and FIB-induced damage for TEM and APT analyses. This controlled environment is integrable to current APT sample transfer system as in [4].

$\mathrm{Al}$ and $\mathrm{Mg}$ metals and their alloys were chosen as test specimens due to their highly oxidizing properties. APT specimens from these materials were prepared on a Si half-grid. The APT specimens were prepared in a FIB system [Thermo Fisher Scientific] using standard lift-out methods and annular milling [5]. Figure 1 shows the APT specimen preparation workflow from FIB to an $\mathrm{Ar}^{+}$milling system [Fischione Instruments] using a FIB vacuum transfer system [Quorum Technologies]. For ease of specimen handling and transfer, the half-grid with the APT specimens was secured in the cartridge of a TEM vacuum transfer specimen holder [Fischione Instruments] that is compatible with the ion milling system. $\mathrm{Ar}^{+}$milling was performed by rastering the beam longitudinally within a defined area on the APT specimen at decreasing milling energies. TEM, energy dispersive X-ray spectroscopy (EDS), and APT characterization were performed before and after ion milling to determine the removal of surface oxides and FIB-induced damage.

EDS at $2 \mathrm{kV}$ ( Figure 2a) acquired from the Al APT specimen (boxed area in Fig. 2b and 2c) after FIB milling and after $\mathrm{Ar}^{+}$milling at ambient conditions show a decrease in $\mathrm{O}$ and Ga signals. EDS maps (Fig. 2bc) indicate that the significant amount of oxygen is associated with the Pt cap; this was removed during $\mathrm{Ar}^{+}$ milling at $1.5 \mathrm{kV}$, followed by $900 \mathrm{eV}$. Therefore, the detected oxygen (Fig. 2a) is mostly from the ambient transfer from the FIB to or from the ion milling system. The slightly lower $\mathrm{O}$ signal after $\mathrm{Ar}^{+}$milling compared to after FIB $5 \mathrm{kV}$ in an uncontrolled environment already shows the elimination of surface oxides. Most importantly, the absence of Ga peak demonstrates removal of Ga damage after $\mathrm{Ar}^{+}$milling. Post-FIB $\mathrm{Ar}^{+}$milling and characterization (EDS, TEM, and APT) under controlled environment are underway.

References:

[1] CS Bonifacio et al., Microscopy and Microanalysis 23 (2017), p. 268.

[2] CS Bonifacio et al., Microscopy and Microanalysis 24 (2018), p. 1118.

[3] CS Bonifacio et al., $19^{\text {th }}$ International Microscopy Congress (2018), p. 669. 
[4] DE Perea et al., Advanced Structural and Chemical Imaging 3 (2017), p. 12.

[5] K Thompson et al., Ultramicroscopy 107 (2007), p. 131.

\begin{tabular}{|c|c|c|c|c|}
\hline Bulk samples & SEM/FIB & Concentrated ion beam milling & & TEM/STEM \\
\hline $\begin{array}{l}\text { Metal }(\mathrm{Al}, \mathrm{Mg}) \\
\text { and their alloys }\end{array}$ & $\begin{array}{l}\text { - APT specimen preparation using } \\
\text { Ga ions } \\
\text { - EDS elemental analysis before and } \\
\text { after ion milling }\end{array}$ & $\begin{array}{l}\text { - TEM vacuum transfer specimen } \\
\text { holder inserted into the ion } \\
\text { milling system } \\
\text { - Post-FIB processing of APT } \\
\text { specimens }\end{array}$ & $\bullet \bullet$ & $\begin{array}{l}\text { - Structure and morphology } \\
\text { - Atomic resolution imaging } \\
\text { - Elemental analysis and } \\
\text { identification of oxidation } \\
\text { states by EELS }\end{array}$ \\
\hline - Vacuum transfer & \multicolumn{2}{|c|}{ Glove box with positive pressure or inert gas (argon) environment } & & APT \\
\hline $\begin{array}{l}\text { specimen holder } \\
\text { FIB vacuum transfer } \\
\text { system } \\
\text { APT vacuum transfer } \\
\text { system }\end{array}$ & \multicolumn{2}{|c|}{$\begin{array}{l}\text { (1) FIB lift-out APT specimen loaded into a vacuum transfer specimen } \\
\text { holder for ion milling } \\
2 \text { lon-milled APT specimen moved to SEM for elemental analysis } \\
\text { (3) APT specimen loaded in a vacuum transfer specimen holder }\end{array}$} & 3 & $\begin{array}{l}\text { - Structure and morphology } \\
\text { - Identification of oxidation } \\
\text { states }\end{array}$ \\
\hline
\end{tabular}

Figure 1. Workflow of APT specimen preparation with post-FIB polishing step and correlative characterization under controlled environments.
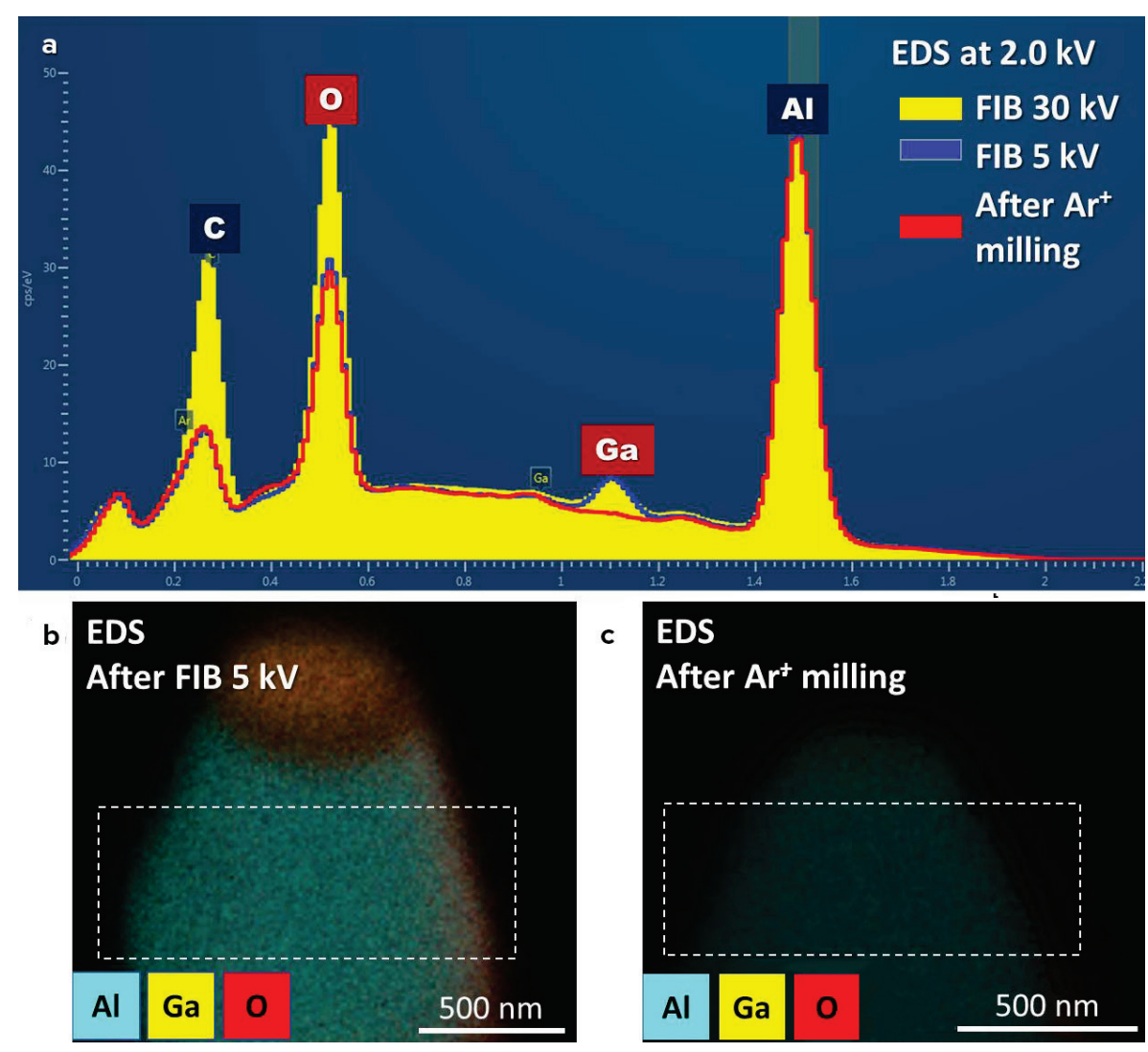

Figure 2. EDS spectra at $2 \mathrm{kV}$ (a) acquired from an Al APT specimen prepared at ambient conditions. After $5 \mathrm{kV}$ FIB, the $\mathrm{O}$ and $\mathrm{Ga}$ are mostly distributed at the cap and on all surfaces of the APT specimen (b). After $5 \mathrm{kV}$ FIB followed by $\mathrm{Ar}^{+}$milling, no $\mathrm{Ga}$ and some $\mathrm{O}$ are detected (c). 